17 Stanhope R, Albanese A, Shalet S. Delayed puberty. Many good arguments to treat. $B M F$ 1992; 305: 790.

18 Odonkor PO, Addae SK. Circulating testosterone in adolescent and young adult sickle cell disease patients. IRCS 1982;10: 302 .

19 Heyman MB, Vichinsky E, Katz R, et al. Growth retarda- tion in sickle cell disease treated by nutritional support. Lancet 1985; ii: 903-6.

20 Singhal A, Davies P, Sahoota A, Thomas PW, Serjeant GR. Resting metabolic rate in homozygous sickle cell disease. Am f Clin Nutr 1993; 57: 32-4.

\title{
Why do they wheeze so much?
}

Atmospheric pollutants which may affect respiratory health include smoke, sulphur dioxide $\left(\mathrm{SO}_{2}\right)$, ozone, oxides of nitrogen, sulphate, hydrogen ion, and carbon monoxide. A paper from Birmingham (Sarah Walters and colleagues, Thorax $1994 ; 49: 133-40$ ) reports on the relationship between air concentrations of smoke and $\mathrm{SO}_{2}$ and hospital admissions of people of all ages for asthma and other respiratory diseases in the city during the two years ending March 1990.

Despite the fact that the concentrations of smoke and $\mathrm{SO}_{2}$ were within EEC guidelines throughout (apart from one day) there was a significant association between these concentrations and daily hospital admissions in winter for all respiratory illnesses and for asthma. Mean (maximum) daily air concentrations of smoke were $12 \cdot 7(188 \cdot 3) \mu \mathrm{g} / \mathrm{m}^{3}$ and of $\mathrm{SO}_{2} 39 \cdot 1(126 \cdot 3)$ $\mu \mathrm{g} / \mathrm{m}^{3}$. It was estimated that in winter a rise in smoke concentration of $100 \mu \mathrm{g} / \mathrm{m}^{3}$ might result in 21 more admissions to Birmingham hospitals each day for respiratory illnesses including five for asthma. An identical rise in $\mathrm{SO}_{2}$ might give four more asthma and 15 more total respiratory admissions. The increase in admissions tended to follow the increase in pollution by about two days. No separate information is given about children but in an American study increased air pollution resulted in a $47 \%$ rise in hospital admissions for adults and an $87 \%$ rise for children. ${ }^{1}$ It seems therefore that short term increases in smoke and $\mathrm{SO}_{2}$ air pollution are associated with increased respiratory morbidity even when the levels remain within EEC suggested limits. Nevertheless, there has been no increase in such pollution over the last 30 years and it cannot explain the increased prevalence of asthma in recent years.

So why is asthma on the increase? The question is considered by Anthony Seaton and co-writers in the same issue of Thorax $(1994 ; 49: 171-4)$. In the last 20 years the prevalence of both asthma and eczema has doubled in Britain and hay fever has become three or four times more common. In Australia and New Zealand there has also been a twofold increase in childhood asthma. Yet atmospheric pollution in Britain does not compare with that of the 1950s. There has been no increase in any measured pollutant adequate to explain the epidemiological data. Neither has there been a rise in the main indoor air pollutant, tobacco smoke, or in exposure to house dust mite or domestic animals.

There is evidence that where societies have become 'westernised' and where people have migrated to westernised societies an increase in the prevalence of asthma has followed. Over the relevant period there has been a change in British dietary habits and these authors argue that this change could be the cause of the increase in atopic disease. In the 25 years up to 1985 people in Britain ate considerably less fresh fruit and vegetables, potatoes, meat, and fish. These foods are all important sources of antioxidants. The suggestion is that the increase in disease could be a result of the effects of oxygen free radicals unopposed by natural antioxidants. It is clearly a hypothesis which needs to be addressed. We are in the middle of a major epidemic which we can no longer tolerate with any degree of equanimity. Who is going to remove the handle from the parish pump of this disease?

ARCHIVIST 